
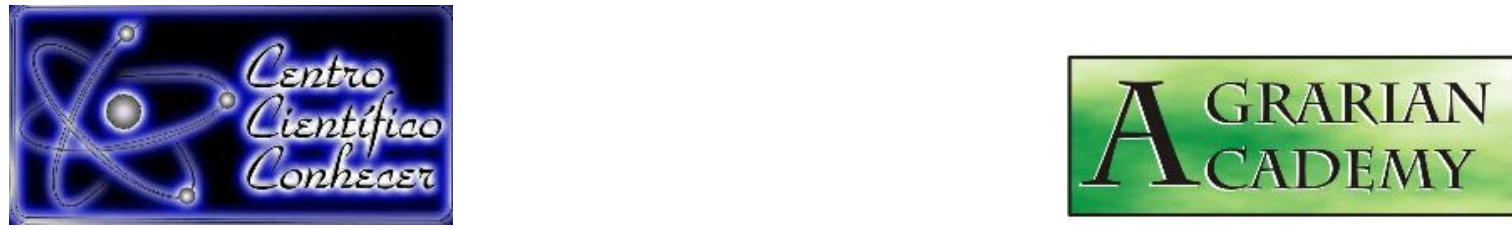

\title{
PERSPECTIVA ECONÔMICA DA IMPLANTAÇÃO DE ARROZ DE TERRAS ALTAS NO SUDESTE DE GOIÁS
}

Francielle Wanderley Ribeiro ${ }^{1}$, Carolina Candida Rodrigues ${ }^{1}$, Stefânia Alves Peixoto $^{1}$, Andrécia Cósmem da Silva ${ }^{2}$, Matheus da Silva Araújo ${ }^{3}$

1. Discentes do Curso de Agronomia da Universidade Estadual de Goiás, Campus

Ipameri, Ipameri, GO, Brasil. (fran3wanderley@gmail.com)

2. Prof ${ }^{a}$ Mestre da Universidade Estadual de Goiás, Campus Ipameri, Ipameri, $\mathrm{GO}$, Brasil.

3. Doutorando em Solos e Nutrição de Plantas da Universidade de São Paulo, Campus ESALQ, Piracicaba, SP, Brasil.

Recebido em: 19/11/2018 - Aprovado em: 14/12/2018 - Publicado em: 25/12/2018 DOI: 10.18677/Agrarian_Academy_2018B15

\section{RESUMO}

O arroz é um alimento de valor nutricional elevado que está presente na alimentação humana desde os primórdios da civilização. No Brasil possui dois diferentes tipos de condução da cultura, os de várzea e de terras altas. Em consequência das características da região de Goiás, o objetivo desse estudo foi realizar uma estimativa dos custos de produção da cultura do arroz de terras altas e assim, analisar a viabilidade econômica em uma propriedade rural na região sudeste de Goiás. Desta forma realizou-se a análise do projeto por meio dos seguintes indicadores econômicos: o Valor Presente Líquido (VPL), Taxa Interna de Retorno (TIR), a Razão Benefício Custo (BC) e Payback atualizado. Fez-se o uso da análise de sensibilidade com a finalidade de avaliar possíveis cenários que podem ser atingidos no decorrer do processo de produção da cultura. As análises apresentaram valores satisfatórios para implantação da atividade, com seguintes resultados; VPL = $20.274,77, \mathrm{~B} / \mathrm{C}=1,23$, TIR $27 \%$ e Payback atualizado no $3^{\circ}$ ano. Diante às condições de estudo nota-se que o projeto apresenta viabilidade econômica, o que demonstra que arroz é uma fonte alternativa de renda para a região sudoeste de Goiás.

PALAVRAS-CHAVE: Agricultura, indicadores econômicos, rizicultura.

\section{ECONOMIC PERSPECTIVE OF THE IMPLEMENTATION OF HIGHLANDS IN THE SOUTHEAST OF GOIÁS}

\footnotetext{
ABSTRACT

Rice is a food of high nutritional value that is present in food since the dawn of civilization. In Brazil has two different types of driving culture, and lowland Highlands. As a result of the characteristics of the region of Goiás, the aim of this study was to perform an estimate of the cost of production of the rice culture of the Highlands and so, analyze the economic viability in a country estate in the Southeast region of AGRARIAN ACADEMY, Centro Científico Conhecer - Goiânia, v.5, n.10; p. 1502018
} 
Goiás. In this way the project analysis through the following economic indicators: net present value (NPV), internal rate of return (IRR), the Benefit Cost Ratio (BC) and Payback updated. Did the use of sensitivity analysis in order to evaluate possible scenarios that can be achieved in the course of the production process of culture. The results showed satisfactory values for deployment of the activity, with a VPL $=$ 20,274.77, B/C $=1.23$, TIR $=27 \%$ and Payback updated on 3rd grade. On the conditions of the study note that the project presents economic viability, which shows that rice is an alternative source of income for the region southwest of Goiás.

KEYWORDS: Agriculture, economic indicators, riziculture.

\section{INTRODUÇÃO}

O arroz (Oryza sativa L.) está presente na alimentação humana desde os primórdios da civilização, originário do sudeste da Ásia, incluindo a região da Índia, China e a Indochina, os quais apresentam cerca de $58 \%$ da população mundial, consumindo cerca de $90 \%$ da produção do cereal. Introduzido no Brasil no ano de 1540, na capitania de São Vicente, a produção disseminou pelo litoral brasileiro, principalmente no Nordeste, onde em 1904 surgiram as primeiras lavouras irrigadas do país (BASSINELLO; CASTRO, 2004).

É um alimento de valor nutricional elevado, destacando-se na constituição da dieta básica dos seres humanos. Apresenta grande fonte energética, rico em proteínas e sais minerais como fosfato, ferro e cálcio, vitaminas do complexo $B$, além de fornecer carboidratos, a proteína se espalha pelo grão inteiro, tornando-o de fácil digestão (NAVES, 2007).

No Brasil, é cultivado em dois tipos de ecossistemas, os de várzeas (35\%), e em terras altas (65\%) em diferentes formas de condução. Apesar do arroz de terras altas apresentar maior área de cultivo, a produtividade é baixa representando apenas $45 \%$ da produção nacional do cereal (CONAB, 2013).

A produção de arroz de terras altas no Brasil passa por um momento de redução gradativa, apresentando queda de $22,7 \%$ na área plantada em um período de 10 anos. O cenário do estado de Goiás não se mostra diferente, a área cultivada no estado teve redução de $71,5 \%$, passando de 111,2 mil hectares na safra 2005/06 para 31,7 mil hectares na safra 2014/15. Afetando não só o fator área plantada, mas também a quantidade produzida, Goiás passou de 206,8 mil toneladas na safra 2005/06 para 112,6 mil toneladas na safra 2014/15 (CONAB, 2015).

Em muitas regiões o cultivo de arroz de terras altas é utilizado principalmente para a abertura de área, como cultivo inicial em áreas de cerrado, em consequência da baixa exigência por nutrientes e melhorias proporcionadas ao solo, permitindo a substituição por soja ou por pastagens. Contudo, o sistema mais propício para essa cultura seria a aplicação desta como cultura rotacional para a soja (GODOY et al., 2015).

Com o intuito de verificar a consistência e a rentabilidade de um projeto, tem sido cada vez mais utilizada a análise econômica, que consiste-se em uma atividade que visa realizar a identificação dos benefícios possíveis de serem obtidos a partir da implementação de um projeto (ZAGO et al. 2009). Assim, para que seja realizado um cultivo economicamente viável, é necessária realização correta do manejo, de modo a obter maior produção, para isso é indispensável que o produtor realize o estudo econômico (CARVALHO et al., 2011).

Diante do exposto, o objetivo desse projeto foi realizar a estimativa dos custos de produção da cultura do arroz de terras altas e assim, analisar a viabilidade econômica em uma propriedade rural na região sudoeste de Goiás. 


\section{MATERIAL E MÉTODOS}

O estudo de projeção foi realizado considerando as características da fazenda da Universidade Estadual de Goiás, Campus Ipameri. A área de análise está localizada no município de Ipameri - GO com as coordenadas $17^{\circ} 43^{\prime} 19^{\prime \prime} \mathrm{S}$, $48^{\circ} 09^{\prime} 35^{\prime} \mathrm{W}$ e altitude de $762 \mathrm{~m}$, foi destinado um território de 10 hectares para a condução do projeto. De acordo com a classificação de Köppen, o clima da região é definido como tropical úmido, apresentando temperaturas elevadas com chuvas no verão e seca no inverno, com temperatura média de $20^{\circ} \mathrm{C}$ (ALVARES et al., 2013).

O solo da propriedade apresenta textura argilosa, e é classificado como Latossolo Vermelho-Amarelo, seguindo a nomenclatura do Sistema Brasileiro de Classificação de Solos (EMBRAPA, 2013). Seguindo as orientações dispostas pelo Ministério da Agricultura, Pecuária e Abastecimento (MAPA, 2018), a cultivar utilizada para a condução do projeto foi a BRS Primavera.

Para a condução do projeto primeiramente foi realizada a análise química da área experimental, com o intuito de levantar uma estimativa mais precisa para a região, a partir das amostras coletadas obteve-se o seguinte resultado: $\mathrm{pH}\left(\mathrm{CaCl}_{2}\right)=$ 4,$4 ; \mathrm{H}+\mathrm{Al}=47 \mathrm{mmol}_{\mathrm{c}} \mathrm{dm}^{-3} ; \mathrm{Ca}=7 \mathrm{mmol}_{\mathrm{c}} \mathrm{dm}^{-3} ; \mathrm{Mg}=3 \mathrm{mmol}_{\mathrm{c}} \mathrm{dm}^{-3} ; \mathrm{P}$ (resina) $=5$ $\mathrm{mg} \mathrm{dm}{ }^{-3} ; \mathrm{K}=2,4 \mathrm{mmol}_{\mathrm{c}} \mathrm{dm}^{-3}$; Matéria orgânica $=33 \mathrm{~g} \mathrm{dm}^{-3} ;$ CTC $=59 \mathrm{mmol}_{\mathrm{c}} \mathrm{dm}^{-3}$; $\mathrm{V} \%=21 ; \mathrm{Cu}=1,2 \mathrm{mg} \mathrm{dm}^{-3}, \mathrm{Fe}=66 \mathrm{mg} \mathrm{dm}^{-3}, \mathrm{Mn}=6,9 \mathrm{mg} \mathrm{dm}^{-3}, \mathrm{Zn}=0,6 \mathrm{mg} \mathrm{dm}^{-3}, \mathrm{e}$ $\mathrm{B}=0,12 \mathrm{mg} \mathrm{dm}^{-3}$.

A cultivar escolhida caracteriza-se por possui porte médio, apresentando dimensões que variam de 110 a $120 \mathrm{~cm}$, o ciclo é curto, com a média de 112 dias, os grãos são longos e finos, dando nome ao arroz por agulhinha. O preparo do solo foi realizado por meio da escarificação e duas gradagens, uma antes da aplicação do calcário, em que foi aplicado 2,5 T.ha ${ }^{-1}$, no intuito de realizar o controle da acidez do solo, posteriormente foi feita a segunda gradagem com a finalidade de desagregar e nivelar o solo, após esses procedimentos foi adicionado a adubação em sulcos de 0,35 T.ha' ${ }^{-1}$ de NPK.

Determinou-se que a semeadura seja realizada mecanicamente com semeadora de 14 linhas de $0,50 \mathrm{~m}$, utilizando $80 \mathrm{Kg}$ de semente por hectare o que totalizou em 2.200.000 plantas. ha $^{-1}$, as sementes foram tratadas com uma dosagem de fungicida de $0,16 \mathrm{Kg} \cdot \mathrm{ha}^{-1}$. Após a semeadura realizou-se a adubação de cobertura, com a aplicação de $170 \mathrm{Kg}$. ha- ${ }^{-1}$ de uréia $(45 \% \mathrm{~N})$. Iniciou-se a aplicação de 0,6 L.ha $^{-1}$ de inseticida após 15 dias do plantio. Depois de 40 dias da semeadura realizou-se a aplicação de fungicida em uma proporção de 0,6 L.ha ${ }^{-1}$, junto à 0,5 L.ha ${ }^{-1}$ de óleo mineral, visando melhor aproveitamento do produto.

Para colheita recomendou-se a utilização de maquinários terceirizados, uma vez que a propriedade não possui maquinários apropriados para a cultura. $O$ valor do aluguel das máquinas ficou em $5 \%$ da produção de tudo que for colhido, ao final será repassado esse valor a empresa terceirizada. A projeção de sacas foi de 58 sc.ha ${ }^{-1}$, e a comercialização do produto ocorreu com o preço estimado da saca de 60 kg por $\mathrm{R} \$ 55,00$, conforme valor do mercado local no mês de Janeiro de 2018.

A formulação da tabela dos coeficientes técnicos necessários para a condução da cultura na região Sudoeste de Goiás foi feita por meio de entrevistas com pesquisadores do setor que possuem conhecimento técnico referente a cultura e também com o auxílio de boletins técnicos direcionados para o arroz, descritos por Ifag (2018). As cotações de custos e receitas descritas no trabalho foram levantadas em mercado local, possibilitando a obtenção do real potencial econômico da cultura para a região. 
De acordo com Rambo et al. (2015) e Martin et al. (1998), os custos foram dispostos em Custo Operacional Efetivo (COE), que considera-se o somatório de insumos (adubos, calcário, inseticida, fungicida, herbicida), operações mecânicas (distribuição de calcário, pulverizações, plantio, adubação), serviços terceirizados (colheita e transporte) utilizados na condução da cultura. Enquanto que o Custo Operacional Total (COT) é composto pelo somatório do COE com as despesas de recursos humanos, impostos e outros custos, que refere-se a despesas eventuais durante a condução da cultura.

A análise econômica foi realizada por meio do fluxo de caixa que consiste em discriminar as receitas e despesas referentes ao período de estudo analisando o saldo de caixa (GITMAN, 2000). Para verificar a viabilidade do projeto, utilizaram-se os seguintes indicadores econômicos: o Valor Presente Líquido (VPL), Taxa Interna de Retorno (TIR), a Razão Benefício Custo (BC) e Payback atualizado.

O Valor Presente Líquido (VPL) consiste em calcular os valores de entrada e saídas de caixa, ou seja, é a somatória de todos os capitais procedentes das receitas produzidas, subtraído da soma das despesas cometidas ao longo da vida útil do empreendimento, atualizados a partir da taxa de desconto do capital, adotada pelo investimento (LUCENA et al., 2016).

Se os cálculos apresentarem um VPL $>0$, o projeto é considerado como viável, isto é, o valor da receita do projeto é maior do que o do investimento inicial, tendo o produtor um retorno financeiro (CARREIRA; SANTOS, 2017). O VPL é calculado pela fórmula 1:

$\mathrm{VPL}=\sum_{\mathrm{t}=0}^{n} \frac{\mathrm{FC}_{\mathrm{t}}}{(1+\mathrm{i})^{\mathrm{t}}}$

Sendo:

$\Sigma$ : somatório;

FC: fluxo de caixa do período $n$;

i: taxa de desconto;

t: período;

A Taxa Interna de Retorno (TIR) é definida como a taxa que reduz a receita esperada ao ponto de iguala-la ao valor das despesas possíveis. Desta forma o VPL é igualado a zero. Calculado pela fórmula 2. (SANTOS FILHO et al., 2016).

$0=\sum_{\mathrm{t}=0}^{n} \frac{P C_{\mathrm{t}}}{(1+i)^{\mathrm{t}}}$

A Razão Benefício Custo $(\mathrm{BC})$ é definida por meio da divisão entre a relação do valor presente dos benefícios e o valor presente dos custos da propriedade. Assim, o empreendimento será economicamente viável se apresentar um valor da razão benefício/custo maior que uma unidade de capital investido, sendo considerado viável quanto maior for seu valor (ALMEIDA et al., 2017). Utilizando a fórmula 3 para seu cálculo:

$\mathrm{BC}=\frac{\sum_{j=0}^{\mathrm{n}} \mathrm{R}_{\mathrm{j}} /(1+\mathrm{i})^{\mathrm{j}}}{\sum_{\mathrm{j}=0}^{\mathrm{n}} \mathrm{C}_{\mathrm{j}} /(1+\mathrm{i})^{\mathrm{i}}}$

Sendo:

$\mathrm{i}$ = Taxa de desconto; 
$\mathrm{R} \mathrm{j}=$ Receitas oriundas do projeto no ano j;

$\mathrm{C} \mathrm{j}=$ Custos do projeto no ano $\mathrm{j}$;

$\mathrm{n}=$ Vida útil do projeto;

O Payback atualizado é utilizado para comprovar o tempo necessário para que as receitas possam cobrir o capital investido. Segundo Paraense et al., (2013) este método tem como princípio, considerar a dimensão do tempo de capital, a partir da atualização do fluxo líquido. Para o cálculo é utilizada a fórmula 4:

Payback $=\sum_{i=0}^{k} \frac{F_{i}}{(1+i)^{1}} \geq 0$ e $\sum_{i=0}^{k-1} \frac{F_{i}}{(1+i)^{i}}<0$

Sendo:

$\mathrm{k}=$ Total de períodos do projeto;

$\mathrm{Fi}=$ Fluxo de caixa no ano i;

$\mathrm{j}=$ Taxa de juros considerada;

i = Número de períodos;

Seguido à análise de viabilidade econômica realizou-se a análise de sensibilidade, que de acordo com Virgens et al., (2015) é uma forma de propor situações que variem o contexto de produção, preço e comercialização, de modo a compor um cenário real, no estudo foram utilizados os indicadores VPL, TIR, BC e Payback, considerando os cenários: Real, Otimista e Pessimista.

Cenário Real: As informações permanecem sem variações.

Cenário Otimista: Redução de $10 \%$ nos custos e aumento de $10 \%$ na produtividade.

Cenário Pessimista: Aumento de $10 \%$ nos custos e redução de $10 \%$ na produtividade.

As análises dos dados foram obtidas durante a safra 2017/2018, com um estudo estimado com um horizonte de cinco anos. A taxa de desconto de 6,56\% a.a. de acordo com a Taxa de Juros de Longo Prazo (BNDES, 2018). Os dados foram tabulados utilizando planilha do Microsoft Excel.

\section{RESULTADOS E DISCUSSÃO}

Diante das análises realizadas no decorrer do estudo, foi possível estimar a composição dos custos necessários para a implantação do empreendimento com a cultura de arroz em uma área de 1 hectare e para área de 10 hectares (Tabela 1). Analisando a área de 10 ha, nota-se que foi obtido um COT de R\$24.305,67 para a produção de 580 sacas de $60 \mathrm{Kg}$ de arroz, os custos foram dispostos em insumos, operações mecânicas, mão de obra, custo com oportunidade de terra, funrural e outros custos.

TABELA 1. Estimativa do custo de produção por hectare e em área total de 10 ha da cultura do arroz.

\begin{tabular}{cccccc}
\hline Descrição & Unidade & Quantidade & Valor unitário & Valor 1 ha & Valor 10 ha \\
\hline Insumos & \multicolumn{7}{c}{} \\
Calcário & $\mathrm{T}$ & 2,5 & $\mathrm{R} \$ 115,00$ & $\mathrm{R} \$ 287,50$ & $\mathrm{R} \$ 2.875,00$ \\
Semente & $\mathrm{Kg}$ & 80 & $\mathrm{R} \$ 2,10$ & $\mathrm{R} \$ 168,00$ & $\mathrm{R} \$ 1.680,00$ \\
Adubo NPK & $\mathrm{T}$ & 0,35 & $\mathrm{R} \$ 1.737,00$ & $\mathrm{R} \$ 607,95$ & $\mathrm{R} \$ 6.079,50$ \\
Uréia & $\mathrm{Kg}$ & 170 & $\mathrm{R} \$ 1,40$ & $\mathrm{R} \$ 238,00$ & $\mathrm{R} \$ 2.380,00$ \\
Inseticida & $\mathrm{L}$ & 0,6 & $\mathrm{R} \$ 77,00$ & $\mathrm{R} \$ 46,20$ & $\mathrm{R} \$ 462,00$ \\
Fungicida & $\mathrm{L}$ & 0,6 & $\mathrm{R} \$ 38,00$ & $\mathrm{R} \$ 22,80$ & $\mathrm{R} \$ 228,00$
\end{tabular}

AGRARIAN ACADEMY, Centro Científico Conhecer - Goiânia, v.5, n.10; p. 1542018 


\begin{tabular}{|c|c|c|c|c|c|}
\hline Óleo Mineral & L & 0,5 & $\mathrm{R} \$ 20,00$ & $\mathrm{R} \$ 10,00$ & $\mathrm{R} \$ 100,00$ \\
\hline \multicolumn{6}{|l|}{$\begin{array}{l}\text { Operações } \\
\text { Mecânicas }\end{array}$} \\
\hline Escarificação & $\mathrm{HM}$ & 0,5 & $\mathrm{R} \$ 70,00$ & $\mathrm{R} \$ 35,00$ & $R \$ 350,00$ \\
\hline Gradagem & $\mathrm{HM}$ & 0,3 & $\mathrm{R} \$ 70,00$ & $R \$ 21,00$ & $R \$ 210,00$ \\
\hline Calagem & HM & 0,2 & $\mathrm{R} \$ 70,00$ & $R \$ 14,00$ & $R \$ 140,00$ \\
\hline Plantio & HM & 0,5 & $\mathrm{R} \$ 70,00$ & $R \$ 35,00$ & $\mathrm{R} \$ 350,00$ \\
\hline Cobertura & $\mathrm{HM}$ & 0,3 & $\mathrm{R} \$ 70,00$ & $R \$ 21,00$ & $R \$ 210,00$ \\
\hline Inseticida & $\mathrm{HM}$ & 0,5 & $\mathrm{R} \$ 70,00$ & $R \$ 35,00$ & $\mathrm{R} \$ 350,00$ \\
\hline Fungicida & $\mathrm{HM}$ & 0,5 & $\mathrm{R} \$ 70,00$ & $\mathrm{R} \$ 35,00$ & $\mathrm{R} \$ 350,00$ \\
\hline Colheita & $\mathrm{HM}$ & 0,5 & $\mathrm{R} \$ 70,00$ & $R \$ 35,00$ & $\mathrm{R} \$ 350,00$ \\
\hline \multicolumn{6}{|l|}{ Mão de obra } \\
\hline Escarificação & $\mathrm{DH}$ & 0,1 & $\mathrm{R} \$ 100,00$ & $R \$ 10,00$ & $\mathrm{R} \$ 100,00$ \\
\hline Gradagem & $\mathrm{DH}$ & 0,1 & $R \$ 100,00$ & $\mathrm{R} \$ 10,00$ & $\mathrm{R} \$ 100,00$ \\
\hline Calagem & $\mathrm{DH}$ & 0,1 & $\mathrm{R} \$ 100,00$ & $R \$ 10,00$ & $R \$ 100,00$ \\
\hline Plantio & $\mathrm{DH}$ & 0,2 & $\mathrm{R} \$ 100,00$ & $R \$ 20,00$ & $R \$ 200,00$ \\
\hline Cobertura & $\mathrm{DH}$ & 0,1 & $\mathrm{R} \$ 100,00$ & $R \$ 10,00$ & $R \$ 100,00$ \\
\hline Inseticida & $\mathrm{DH}$ & 0,2 & $\mathrm{R} \$ 100,00$ & $R \$ 20,00$ & $\mathrm{R} \$ 200,00$ \\
\hline Fungicida & $\mathrm{DH}$ & 0,2 & $\mathrm{R} \$ 100,00$ & $R \$ 20,00$ & $\mathrm{R} \$ 200,00$ \\
\hline Colheita & $\mathrm{DH}$ & 0,2 & $\mathrm{R} \$ 100,00$ & $R \$ 20,00$ & $\mathrm{R} \$ 200,00$ \\
\hline $\begin{array}{l}\text { Custo Operacional } \\
\text { Efetivo (COE) }\end{array}$ & & & & $\begin{array}{c}\mathrm{R} \$ \\
1.731,45 \\
\end{array}$ & $\begin{array}{c}\mathrm{R} \$ \\
17.314,50\end{array}$ \\
\hline $\begin{array}{l}\text { Custo com } \\
\text { oportunidade da } \\
\text { terra }\end{array}$ & & 1 & $\mathrm{R} \$ 500,00$ & $\mathrm{R} \$ 500,00$ & $\mathrm{R} \$ 5.000,00$ \\
\hline Funrural & $\%(\mathrm{COE})$ & 1,5 & & $R \$ 25,97$ & $\mathrm{R} \$ 259,72$ \\
\hline Outros custos & $\%(\mathrm{COE})$ & 10 & & $\mathrm{R} \$ 173,15$ & $\mathrm{R} \$ 1.731,45$ \\
\hline $\begin{array}{l}\text { Custo Operacional } \\
\text { Total (COT) }\end{array}$ & & & & $\begin{array}{c}\mathrm{R} \$ \\
2.430,57\end{array}$ & $\begin{array}{c}\mathrm{R} \$ \\
24.305,67\end{array}$ \\
\hline
\end{tabular}

Nota-se na figura 1 que o custo mais expressivo para a implantação da cultura foi com a aquisição dos insumos, representando $56,8 \%$ do total dos custos, seguidos dos custos de oportunidade de terra com 20,57\% do total. Os demais custos foram representados por $9,5 \%$ de operações mecânicas, $7,12 \%$ de outros custos, $4,94 \%$ de mão de obra e $1,07 \%$ de funrural. Em trabalho desenvolvido por Silva e Wander (2017), percebeu-se que os custos analisados para a safra de 2015/2016 apresentou custos de $R \$ 2.173,15$ para 1 ha, pouco inferior ao custo do atual trabalho, que foi de $\mathrm{R} \$ 2.430,57$ para 1 ha. Os custos mais expressivos foram de insumos representados por $46,42 \%$, seguidos de mão de obra com $39,44 \%$ e operações mecânicas com $11,41 \%$. Em consequência das mudanças de mercado no decorrer dos anos, em conjunto com a variação entre as regiões, uma vez que o trabalho foi realizado no estado do Mato Grosso. 


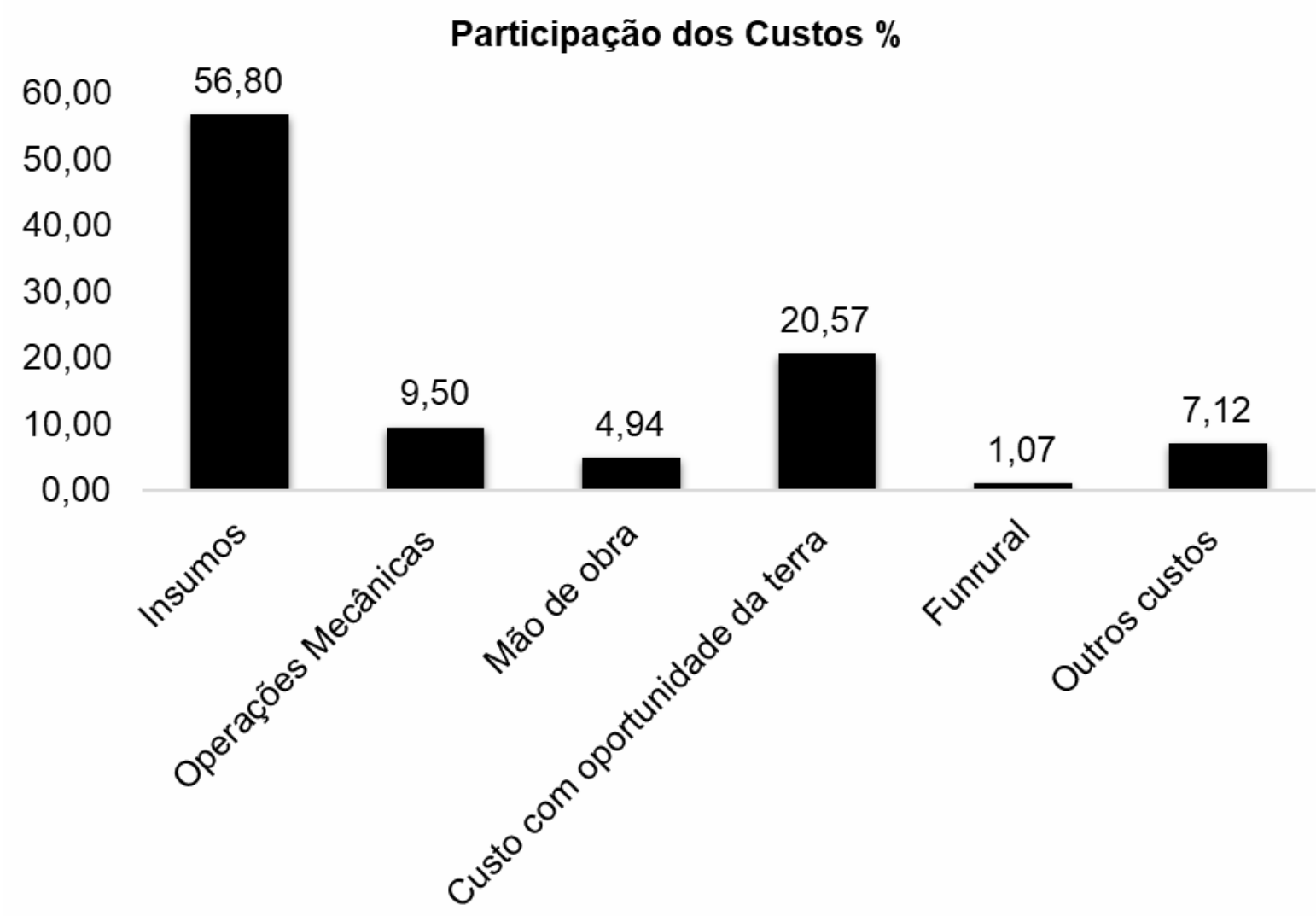

FIGURA 1. Participação dos custos para a implantação de arroz na região Sudeste de Goiás.

Ao analisar a implantação, a produtividade foi de 58 sacas por ha, totalizando 580 sacas em 10 ha. A produção foi vendida a um preço médio de $R \$ 55,00$ por saca, obtendo uma receita de $R \$ 3.190,00$ por ha e uma receita bruta de $R \$$ 31.900,00 em 10 ha (Tabela 2).

TABELA 2. Área produzida - receita da cultura do arroz.

\begin{tabular}{cccccc}
\hline Atividade & Área (ha) & Und. & Quant. & Valor Unitário (R\$) & Valor Total (R\$) \\
Arroz & 1 & Sc & 58 & 55,00 & $3.190,00$ \\
Arroz & 10 & Sc & 580 & 55,00 & $31.900,00$ \\
\hline
\end{tabular}

Na tabela 3 é possível observar o fluxo de caixa obtido por meio do estudo de implantação de 10 ha de arroz de sequeiro em 5 anos, em que no ano zero apresenta-se o custo necessário para a implantação do projeto, desde o preparo da área até a colheita, não demonstrando a receita, em consequência de ser o ano de implantação do projeto. Enquanto que nos demais anos de análise encontram-se os valores de despesas e receitas obtidas no decorrer do projeto.

Analisando o fluxo de caixa nota-se que o retorno dos investimentos ocorre no terceiro ano, levando em consideração as receitas e despesas obtidas no projeto, os quais no decorrer dos anos sofrem alterações referentes à utilização da taxa de juros em longo prazo que realiza a atualização dos custos e receitas no decorrer dos anos. 
TABELA 3. Fluxo de caixa para avaliação econômica do projeto de investimento de 10 ha.

\begin{tabular}{ccccc}
\hline Ano & $\begin{array}{c}\text { Despesa } \\
\text { atualizada (R\$) }\end{array}$ & $\begin{array}{c}\text { Receita } \\
\text { atualizada (R\$) }\end{array}$ & $\begin{array}{c}\text { Fluxo } \\
\text { Atualizado (R\$) }\end{array}$ & $\begin{array}{c}\text { Fluxo de caixa } \\
\text { acumulado (R\$) }\end{array}$ \\
\hline 0 & & $(24.305,67)$ & $(24.305,67)$ & $(24.305,67)$ \\
1 & $19.172,92$ & $29.936,19$ & $10.763,26$ & $(13.542,41)$ \\
2 & $17.992,61$ & $28.093,27$ & $10.100,66$ & $(3.441,75)$ \\
3 & $16.884,96$ & $26.363,80$ & $9.478,85$ & $6.037,10$ \\
4 & $18.850,84$ & $24.740,81$ & $5.889,97$ & \\
5 & $14.870,02$ & $23.217,72$ & $8.347,70$ & \\
\hline
\end{tabular}

Observa-se na tabela 4 que os indicadores econômicos analisados demonstraram resultados positivos. O VPL foi de $R \$ 20.274,77$, demonstrando o lucro líquido obtido em cinco anos de análise, demonstrando a viabilidade econômica do projeto para as circunstâncias atuais.

No estudo realizado por Rigo et al. (2015), é possível observar que seus custos foram superiores, em consequência da aquisição de novos maquinários agrícolas, benfeitorias na propriedade, acarretando em um estudo inviável economicamente, visto que a diferença entre receita e custo foi negativa (VPL= R $\$$ $892.402,33)$, enquanto que a alternativa de utilizar a terceirização dos serviços torna o custo inferior, viabilizando o projeto.

$\mathrm{O}$ BC apresentou valor de 1,23 , indicando que a cada unidade monetária investida à uma taxa de $6,56 \%$ a.a. haverá um retorno líquido de $R \$ 0,24$ atestando a viabilidade do estudo. Referente ao indicador, exposto em análise feita por Rocha et al. (2017), nota-se o resultado de 1,06, influenciado pela variação do preço de comercialização da saca de arroz.

TABELA 4. Análise econômica dos critérios avaliados.

\begin{tabular}{lcc}
\hline \multicolumn{3}{c}{ Análise econômica } \\
\hline VPL & $20.274,77$ \\
B/C & 1,23 \\
TIR & $27 \%$ \\
Payback atualizado & 3 anos \\
\hline
\end{tabular}

O Payback foi verificado no terceiro ano, momento em que as receitas foram superiores às despesas, resultando em um retorno financeiro do investimento realizado pelo produtor. A análise de sensibilidade descrita na tabela 5 , tem a finalidade de demonstrar a qual ponto pode se encontrar estável uma atividade desenvolvida na propriedade, atribuindo diferentes situações que podem modificar a atual conjuntura do estabelecimento durante a condução do projeto. Neste sentido é possível analisar diferentes cenários que podem ocorrer na propriedade.

TABELA 5. Análise de sensibilidade para o cultivo de arroz.

\begin{tabular}{|c|c|c|c|c|c|}
\hline Cenário & & VPL & $B C$ & TIR & Payback \\
\hline Otimista & $\mathrm{R} \$$ & $41.444,85$ & 1,50 & $52 \%$ & 2 anos \\
\hline Real & $\mathrm{R} \$$ & $20.274,77$ & 1,23 & $27 \%$ & 3 anos \\
\hline Pessimista & $-R \$$ & $8.168,20$ & 0,92 & $-11 \%$ & * \\
\hline
\end{tabular}

Notas: * Não apresentou retorno financeiro no período de análise.

AGRARIAN ACADEMY, Centro Científico Conhecer - Goiânia, v.5, n.10; p. 1572018 
Desta forma observando os resultados da tabela acima, percebe-se a variação existente em cenários distintos que são considerados entre otimista e pessimistas. O otimista favoreceu a implantação do projeto, tornando os lucros superiores ao encontrado no cenário real do estudo, demostrando um VPL de $R \$$ 41.444,85, BC de 1,50, TIR de 52\% e Payback no segundo ano.

Enquanto que no cenário pessimista o projeto foi induzido a uma situação desfavorável, tornando o projeto inviável, demonstrando que nessas situações o VPL foi de $-\mathrm{R} \$ 8.168,20$, BC de 0,92 , TIR de $-11 \%$ e no decorrer dos cinco anos de estudos não foi possível obter um retorno financeiro no período de análise. Demonstrando o quão importante é o monitoramento do produtor durante a condução da cultura, evitando gastos desnecessários e evidenciando a produtividade.

De acordo com as análises concretizadas, todos os critérios se mostraram viáveis economicamente no horizonte de planejamento de cinco nos. Com isso destaca-se que além da viabilidade econômica apresentada pela cultura na região, esta se torna uma fonte de renda para o produtor, pois contribui para a geração de benefícios a propriedade quanto à quantidade de nutrientes disponíveis no solo e no manejo de pragas e doenças, proporcionando redução nos custos de condução da cultura.

\section{CONCLUSÃO}

A implantação da cultura do arroz de terras altas na propriedade estudada consolidou-se como boa possibilidade de investimento por ser uma fonte alternativa de renda para o proprietário. A instalação desse cereal demonstrou ser uma prática viável para a região sudoeste de Goiás, além de diversificar a produção da fazenda.

\section{REFERÊNCIAS}

ALMEIDA, L. H. F.; CORDEIRO, S. A.; PEREIRA, R. S.; COUTO, L. C.; LACERDA, K, W, S. Viabilidade econômica da produção de caju (Anacardium occidentale L.). Nativa, v. 5, n. 1, p. 9-15, 2017. Disponível em: <http://dx.doi.org/10.5935/23187670.v05n01a02>. doi: 10.5935/2318-7670.v05n01a02

ALVARES, C. A.; STAPE, J. L.; SENTELHAS, P. C.; GONÇALVES, J. L. M.; SPAROVEK, G. Köppen's climate classification map for Brazil. Meteorologische Zeitschrift. $\quad$ v. 22, n. 6, p. 711-728, 2013. Disponível em: <https://doi.org/10.1127/09412948/2013/0507>. doi: 10.1127/0941-2948/2013/0507

BASSINELLO, P. Z.; CASTRO, E. M. Arroz como alimento. Informe Agropecuário, v. 25, n. 222, p.101-108, 2004. Disponível em: < https://www.alice.cnptia.embrapa.br/alice/bitstream/doc/212777/1/BassinellolA.pdf>.

BNDES - Banco Nacional de Desenvolvimento Econômico e Social. Brasília: BNDES. Taxa de juros de longo prazo. Disponível em: https://www.bndes.gov.br/wps/portal/site/home/financiamento/guia/custosfinanceiros/ taxa-juros-longo-prazo-tjlp. Acesso em: 20 set. 2018.

CARREIRA, M. L.; SANTOS, R. C. R. Decisões de Investimento com o Auxílio dos Métodos Determinísticos. Revista Ciência Gerencial, v. 21, n. 34, p. 142-144, 2017. Disponível em: http://www.pgsskroton.com.br/seer/index.php/rcger/article/view/4254/3761. 
CARVALHO, M. A. C.; YAMASHITA, O. M.; ROQUE, C. G.; NOETZOLD, R. Produtividade de arroz no sistema integração lavoura-pecuária com o uso de doses reduzidas de herbicida. Bragantia, v. 70, n. 1, p. 33-39, 2011. Disponível em: < http://www.scielo.br/pdf/brag/v70n1/v70n1a06.pdf>.

COMPANHIA NACIONAL DE ABASTECIMENTO (CONAB). A cultura do arroz. Brasília: Conab, 2015. 180 p. Disponível em: https://www.conab.gov.br/outraspublicacoes/item/download/2523_efd93e81ea2d9ae8f0302a6d4f9cefc6. Acesso em: 15 set. 2018.

COMPANHIA NACIONAL DE ABASTECIMENTO (CONAB). Produção de grãos: safra 2013/13 levantamento. Disponível em: <www.conab.gov.br>. Acesso em 15 set. 2018.

EMBRAPA. Sistema brasileiro de classificação de solos. 3 ed. Brasília: Embrapa Solos, 2013. 201p.

GITMAN, L. J. Princípios de Administração Financeira. 2ed. Pearson, São Paulo, SP, Brasil. 2000. 297p.

GODOY, S. G.; STONE, L. F.; FERREIRA, E. P. B.; COBUCCI, T.; LACERDA, M. C. Correlação entre produtividade do arroz no sistema semeadura direta e atributos do solo. Revista Brasileira de Engenharia Agrícola Ambiental, v. 19, n. 2, p. 119125, 2015. Disponível em: <http://dx.doi.org/10.1590/18071929/agriambi.v19n2p119-125>. doi: 10.1590/1807-1929/agriambi.v19n2p119-125

INSTITUTO PARA O FORTALECIMENTO DA AGROPECUÁRIA DE GOIÁS (IFAG) Estimativa de custo de produção - Arroz Sequeiro, 2018. Disponível em: http://ifag.org.br/custos-de-producao. Acesso em: 25 set. 2018.

LUCENA, H. D.; PARAENSE, V. C.; MANCEBO, C. H. A. Viabilidade econômica de um sistema agroflorestal com cacau e essências florestais de alto valor comercial em Altamira-PA. Revista de Administração e Negócios da Amazônia, v. 8, n.1, p. 7384, 2016. Disponível em: <https://doi.org/10.18361/2176-8366/rara.v8n1p\%25p>. doi: $10.18361 / 2176-8366 /$ rara.v8n1p\%25p

MARTIN, N. B.; SERRA, R.; OLIVEIRA, M. D. M.; ÂNGELO, J. A.; OKAWA, H. Sistema de custos agropecuários - Custagri. Informações Econômicas, v. 28, n. 1, p. 7-28, 1998. Disponível em: < http://www.iea.sp.gov.br/ftpiea/ie/1998/tec10198.pdf>.

NAVES, M. M. V. Características químicas e nutricionais do arroz. Boletim do Centro de Pesquisa de Processamento de Alimentos. v. 25, n. 1, p. 51-60, 2007. Disponível em: < https://revistas.ufpr.br/alimentos/article/view/8394/5843>. Acesso em: 25 set. 2018

PARAENSE, V. C.; MENDES, F. A. T. FREITAS, A. D. D. Avaliação econômica de sistemas agroflorestais de cacau e mogno na transamazônica: um estudo de caso. Enciclopédia Biosfera, v. 9, n. 16; p. 2754-2764, 2013. Disponível 
em:<http://dx.doi.org/10.18361/2176-8366/rara.v8n1p73-84>. doi: 10.18361/21768366/rara.v8n1p73-84

RAMBO, J. R.; TARSITANO, M. A. A.; KRAUSE, W.; LAFORGA, G.; SILVA, C.; Análise financeira e custo de produção de banana-maçã: um estudo de caso em Tangará da Serra, Estado do Mato Grosso. Informações econômicas, v. 45, n. 5, 2015. Disponível em: <http://www.iea.sp.gov.br/ftpiea/publicacoes/ie/2015/tec41015.pdf>.

RIGO, F. D.; SCHRIPPE, P.; MEDEIROS, F. S. B.; WEISE, A. D. Viabilidade econômico-financeira de um projeto de produção de arroz na cidade de Agudo - RS. Engevista, v. 17, n. 1, p. 105-112, 2015. Disponível em: <https://doi.org/10.22409/engevista.v17i1.645>. doi: 10.22409/engevista.v17i1.645

ROCHA, A. M.; LOREZON, J; PAULA, R. P.; MAIA, R. V.; FELITO, R. A.; ROBOREDO, D. Viabilidade econômica da produção de arroz de Terras Altas na Região Médio Norte de Mato Grosso: Um estudo de caso. Revista Espacios, v. 38. n. 3 , p. 3-7. 2017. Disponível em: < http://www.revistaespacios.com/a17v38n03/a17v38n03p03.pdf>.

SANTOS FILHO, L. G.; SANTOS, S. G. A. V.; SILVA, C. E. L. S.; SILVA, R. C. A. V. Utilização de indicadores de viabilidade econômica na produção de tilápia (Oreochromis niloticus) em sistema de recirculação: estudo de caso de uma piscicultura de pequena escala em Parnaíba-PI. Organizações rurais \& Agroindustriais, v. $18, \quad$ n. $4, \quad$ p. 304-314, 2016 . Disponível em: <http://www.redalyc.org/pdf/878/87850554002.pdf>.

SILVA, O. F.; WANDER, A. E. Viabilidade econômica da cultivar de arroz de terras altas BRS Sertaneja. Congresso Sociedade Brasileira de Economia, Administração e Sociologia Rural, Goiânia-GO, 2014.

SILVA, O.F.; WANDER, A.E. Viabilidade econômica da cultivar de arroz de terras altas BRS Esmeralda nos estados de Mato Grosso, Maranhão e Piauí, 2013-2015. Congresso Sociedade Brasileira de Economia, Administração e Sociologia Rural, Goiânia-GO, 2017.

VIRGENS, A. P.; FREITAS, L. C.; LUZ, D. S.; MOREIRA, A. C. D. Análise econômica e de sensibilidade em projetos de reflorestamentos no estado da Bahia. Enciclopédia Biosfera, v. 11, n. 21, p. 120-127, 2015. Disponível em: < http://www.conhecer.org.br/enciclop/2015b/agrarias/analise\%20economica\%20e\%20 de\%20sensibilidade.pdf>.

ZAGO, C. A.; WEISE, A. D.; HORNBURG, R. A. A importância do estudo de viabilidade econômica de projetos nas organizações contemporâneas. VI Convibra - Congresso Virtual Brasileiro de Administração. 2009. 